\title{
The Information - Communication Process in a Business with Outsourcing for the Maintenance of a Complex Technical System
}

\author{
Drago Kraljević, Krešimir Lacković, Robert Šojo
}

\begin{abstract}
This paper discusses the process of communication between service providers and recipients when monitoring and maintaining complex technical systems. This requires sophisticated equipment, trained personnel and special methods and procedures. This is especially true for technical diagnostics, as the most complex form of monitoring and preventive maintenance. The relevant elements of maintenance by state and the experience of engaging an external partner are highlighted, especially when the complete monitoring for process control is performed virtually. In that sense, an information and communication process is proposed to ensure the efficiency of the complete system. The education of the external partner and the connection with the holders of external memories, research institutions and centres of excellence can be emphasized.
\end{abstract}

Keywords: communication; information; maintenance; monitoring; process

\section{INTRODUCTION}

Technical systems, regardless of complexity, must be fully reliable in their operation. Additionally, there is a constant need to ensure reliability, and this is determined by the control and analysis of not only reliability, but also of economic efficiency. In this case, the starting point is to prevent the maintenance of complex technical systems. This applies to industrial plants with a high degree of technological equipment, but also to buildings of various uses that have a very complex management system.

In maintaining complex technical systems, a tendency towards perfection is necessary due to the fact that in such systems, any serious interruption of functioning can cause great economic damage, and can often cause human casualties. Therefore, highly educated personnel, appropriate equipment and methods or procedures are required in the maintenance of such facilities. One of the known methods of preventive maintenance of complex technical systems is technical diagnostics.

Given the accelerated development of techniques and technology, technical systems are becoming increasingly complex, which is why more sophisticated and expert maintenance methods and procedures need to be used accordingly. Since businesses usually do not have enough capacity or resources to monitor scientific advances in maintenance, an external partner can be hired for technical diagnostics. The problem of technical diagnostics becomes on the one hand a technical and on the other an economical cost. In such a situation, it is necessary to conclude analytically which variant is more favourable for the company. Moreover, it should be borne in mind that a complex technical system, if it is to function reliably and efficiently, must have all resources effectively allocated, and it is very difficult to believe that the company has sufficient capacity for technical diagnostics. The previous fact only confirms that the involvement of an external partner for monitoring and controlling the functioning of the system and technical diagnostics is a priority. An external partner usually has the resources at his disposal as it is his business activity and the assumption is that he has the human resources, resources and organization for a high level of productivity and quality. Furthermore, the external partner, in addition to the resources, can be linked to other research institutions, centres of excellence and expert teams. In addition to maintenance, the external partner can simultaneously control the business and technological process and thus constantly diagnose the functioning of each line or phase. With such monitoring, it is often possible to detect from a disturbance at some stage the cause that may be an indicator for a maintenance diagnostic or surgery procedure.

In the teaching part of this content, attention is given to defining the reliability of maintaining complex technical systems. The starting point of the review, along with process monitoring, is technical diagnostics as the most sophisticated and most professional form of maintenance prevention. Given that these are periodic, highly sophisticated operations, outsourcing as an organizational form of implementation is proposed, and the reasons for this approach are outlined. Accordingly, an information and communication system to successfully maintain the technical system with an external partner is proposed.

\section{OUTSOURCING}

Outsourcing can be defined as engaging an external partner to perform certain jobs for which there are no appropriate staffing, technical, or other conditions in an enterprise. The reasons for hiring an external partner may also be the fact that certain jobs will be done better but at a lower cost, because the foreign partner has better equipment and because of working methods. In the regulatory-legal sense, outsourcing is the contractual relationship for the transfer of some of the work or entire business activities to external partners, which in this way takes over one or more business activities of the company [1]. Outsourcing is therefore used to help an economic or public entity effectively perform its core and other activities in the best way while utilizing internal competencies, but at the same time to help mitigate the lack of skills and knowledge 
shortages in areas where the specialty of an external associate is sought [2].

In developed economies, outsourcing has established itself in the last twenty years as a business approach. In this respect, outsourcing has in particular included the following types of business:

- Website design

- Marketing and advertising

- Market research

- Development of mobile applications

- Financing and accounting

- Monitoring and control of the complete technological process.

In businesses and public establishments, the aforementioned jobs need to be supplemented by various types of ancillary work such as cleaning, keeping and maintaining the premises. Particular attention should be paid to the maintenance of complex building objects, machines, equipment, installations and IT hardware and software. Outsourcing has become not only a business approach, but also a philosophy that goes into multiple areas of work. Considering the stated, outsourcing also achieves the following effects [3]:

- Concentration on core business

- Expense reduction

- Availability of products and services at market prices

- Quality improvement

- Greater transparency of costs and services

- Avoiding employment risks and inefficiencies beyond the core business. Availability of modern techniques and technologies for maintaining systems without their own investment.

In addition to these reasons, outsourcing enables the availability of workforce over a contractual time period and has certain advantages, in particular [4]:

- Risk management because the external partner guarantees the quantity, quality and timing of individual jobs

- General efficiency because the outsourcer as a development professional applies all new methods, has more educated and ready personnel and means of work

- The external partner needs the constant development of employees.

Of course, there are some drawbacks in every business philosophy, which are especially the following [5]:

- There is a degree of threat to the security of confidential information if an external partner requires greater access to confidential information about the business of the company and parts of the production process

- To some extent, control over part of the business process performed by an external partner is lost

- Sometimes, the external partner cannot maintain the quality and standards of the business or production process
- By providing services to other clients (competitors), the external partner may come into conflict of interest at the expense of the recipient of the service

- A particular problem is if an external partner enters into a business relationship and comes under difficult business conditions (bankruptcy), when great material damage may occur, because the recipient of the service shares the fate of other bankruptcy creditors.

The main reasons for outsourcing in maintenance are [6]:

- Inexperienced own staff

- Outdated technologies

- Unforeseen hidden costs

- Loss of innovation capacity

- Insufficient experience in organizing and managing maintenance processes.

Outsourcing is a business activity because of its evident advantages such as quality, expertise, equipment, human resources, and labour productivity, and it has recently taken up increasing space in national economies. An increasing number of companies and public institutions, especially their subsidiary activities, are entrusting their external partner. It should be noted that the development of techniques and technology requires increasing efficiency on the one hand and a high level of expertise and quality on the other, which is why external cooperation is in some cases inevitable. This is especially true for the maintenance of complex technical systems, and especially necessary for technical diagnostics as the most complex part of preventive maintenance. All outsourcing companies, especially those that maintain technical systems, need to be extremely knowledgeable and equipped. Moreover, they must be able to take preventative action through the information technology. This means that they need to implement an appropriate information and communication system or process.

\section{TECHNICAL MAINTENANCE}

The results of successful outsourcing implementation are best exemplified by the maintenance of a complex technical system. In this case, this refers to the maintenance of complex building objects and sophisticated machinery and equipment, collectively called technical maintenance. In this case, maintenance is considered to be the procedures carried out preventively and in some cases through monitoring, and in the case of very complex equipment and particularly complex technical systems, technical diagnostics is performed as a special form of preventive maintenance. Furthermore, for some complex technical systems, it is necessary to constantly monitor the operation of complete technology. This means that the goal is to constantly monitor and determine the state of functioning of all lines and their production stages.

Maintenance through state monitoring is occasionally supplemented by a complex test or technical diagnostics. Maintenance of the equipment of high technological level systems and complex technical systems should be entrusted to an external partner because of certain advantages that have 
already been mentioned. This is primarily related to better technical equipment and better equipment for the human resources that the external associate has. Furthermore, the external partner ensures quality, deadlines and lower costs due to higher productivity.

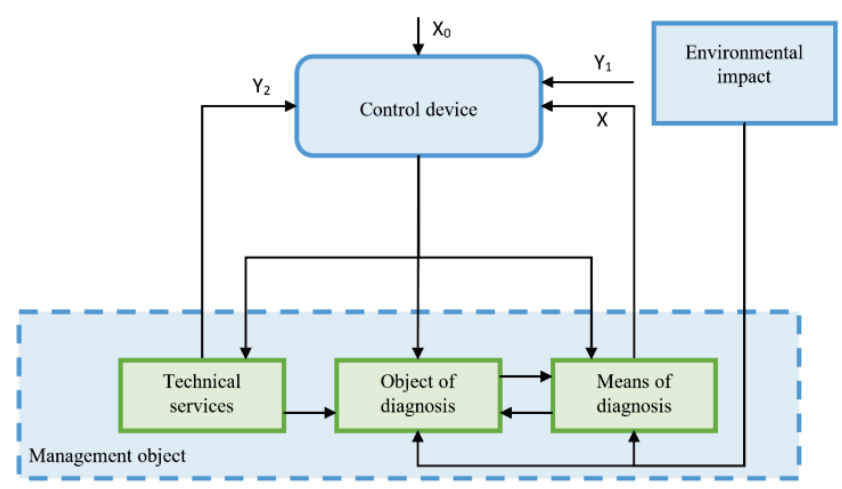

Figure 1 The basic process of technical diagnostics [7]

Technical diagnostics, as shown in Fig. 1, is an organizationally simple system but the methods, procedures, parameters, means and personnel, especially in complex technical systems, are often very complex. Therefore, a detailed description of the process depends on the complexity of the object and the diagnostic parameters and criteria. The maintenance of complex technical systems is a constant monitoring and determination of the condition, and also an undertaking of maintenance activities, i.e. this is actually constant technical diagnostics.

\section{INFORMATION AND COMMUNICATION PROCESS}

In the business of monitoring the technological process and maintaining it with the help of an external partner, especially technical diagnostics, it is necessary to build such an information and communication system so that the recipient of the service can be sure of the maintenance of his business or production system. An effective flow of information and communication between providers and recipients of services can be ensured with a well-organized information system enabled on the provider side. There are experiences and examples for this, such as the well-known CRM (Customer Relationship Management) or customer management [8].

The essence of CRM is that information technology is used to establish a permanent customer relationship. The starting point is one central unit on the service provider side that maintains constant wireless contact between clients and service providers. According to the source, it is actually a single contact centre that can be of lower and higher IT level. This contact centre provides a virtual connection with the recipients of the service. Fig. 2 shows one common contact centre, and it also shows that all information that is relevant and needed to clients is gathered in one place. Additionally, continuous feedback is provided to make communication effective. The provider may be informed of a need (especially an urgent one) at the right time and may act preventively.
The contact centre must be systematically linked to all essential functions of the service provider on the one hand and the customers on the other. This ensures an efficient service and enables immediate intervention when needed. Communication shall be ensured by information means, in particular:

- Different types of communication channels

- Web applications

- Business intelligence applications

- Internal ("background") business applications within the company itself

- Other forms of the Internet.

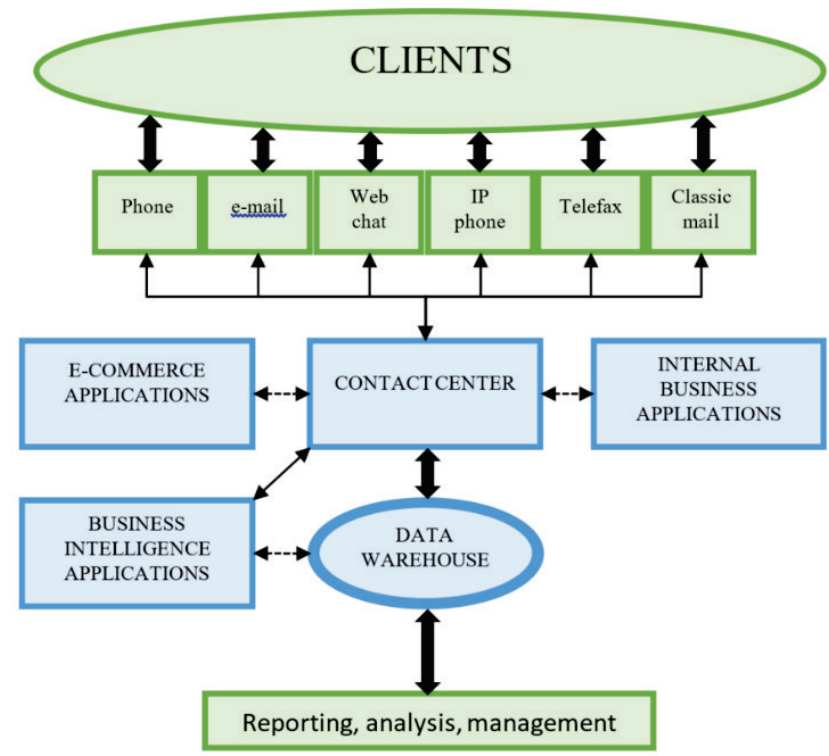

Figure 2 The basic process of technical diagnostics [9]

Regardless of the complexity of the service, the functions of the contact centre are in principle similar, regardless of the type of a technical system, as shown in Fig. 3.

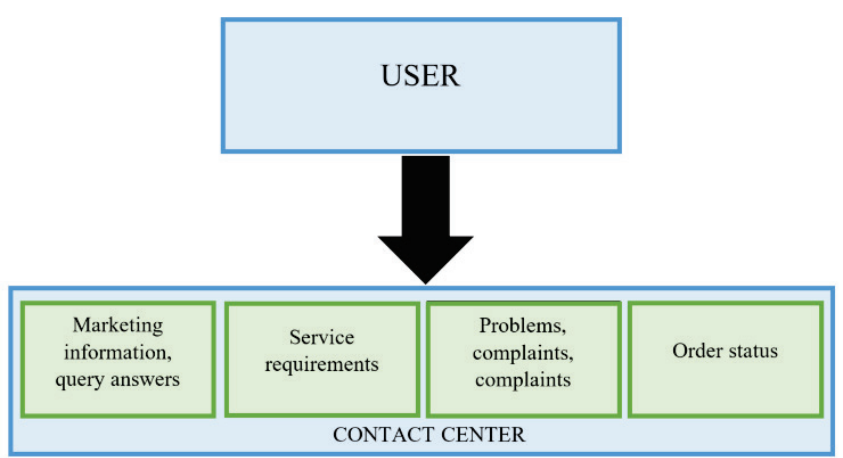

Figure 3 The basic process of technical diagnostics [10]

In the case of technical diagnostics, it is justified to use the proposed approaches as this ensures not only the diagnosis, but also the monitoring of the operation of the system after diagnostics.

Fig. 3 shows the functions or services that companies usually provide to their customers through the contact centre. In the early stages of the development of contact centres, 
these were all marketing information, requests for services and sending offers to customers as well as solving problems arising in mutual cooperation. The development of information technologies has enabled a dynamic two-way communication as shown in Fig. 7. Since the subject of consideration is technical diagnostics, just one complex sophisticated contact centre can provide efficient diagnostics of a complex technical system with high efficiency.

\section{ARCHITECTURE OF THE INFORMATION- COMMUNICATION PROCESS IN MAINTAINING A COMPLEX TECHICAL SYSTEM BY OUTSOURCING}

As it has already been mentioned, external partner services can be simple and very complex. In this case, the goal is to set up an integrated information and communication system to maintain a complex technical system through outsourcing. A complex technical system as a maintenance object implies a large number of stages and an even greater number of operations in certain stages of the process. A specific example of this can be found in larger automated manufacturing facilities, but also in complex construction objects of different uses. In any case, the goal is to maintain and control the process, to act preventively, and often to monitor the condition or functioning.

Certainly, in such systems, the technical diagnostics should especially be entrusted to an external partner, due to a number of afore-mentioned advantages. The efficiency of maintaining and operating a complex system can be ensured by defining and operating an appropriate information and communication system containing appropriate hardware and software.

Fig. 4 shows some production functions by individual stages where costs can be monitored in relation to the time course of production. Mathematically, from Eq. (1), this could be formulated as follows:

$$
Y_{5}(t)=Y_{1}(t)+Y_{2}(t)+Y_{3}(t)+Y_{4}(t)
$$

Eq. (1) is the production function of the process [11]. It shows the legality of the movement of costs over the duration of the process. An external partner can strictly control the process and provide management instructions.

Eq. (1) in conceptual terms represents a mathematical expression where $Y(t)$ represents the total costs of all three production lines and all four operations in the lines. Other labels such as $Y_{1}(t), Y_{2}(t), Y_{3}(t)$ and $Y_{4}(t)$ represent cost flows in individual production lines, which are the sums of the costs of individual stages in each line. In addition to monitoring costs by stages and production lines, it is possible to monitor product quantities, costs per product as well as profit per line, stage and product. The optimal production capacity as well as several indicators in the field of monitoring the condition and functioning of the technical system can be determined. Appropriate software should be installed for each of these types of monitoring in accordance with the mathematical expression.

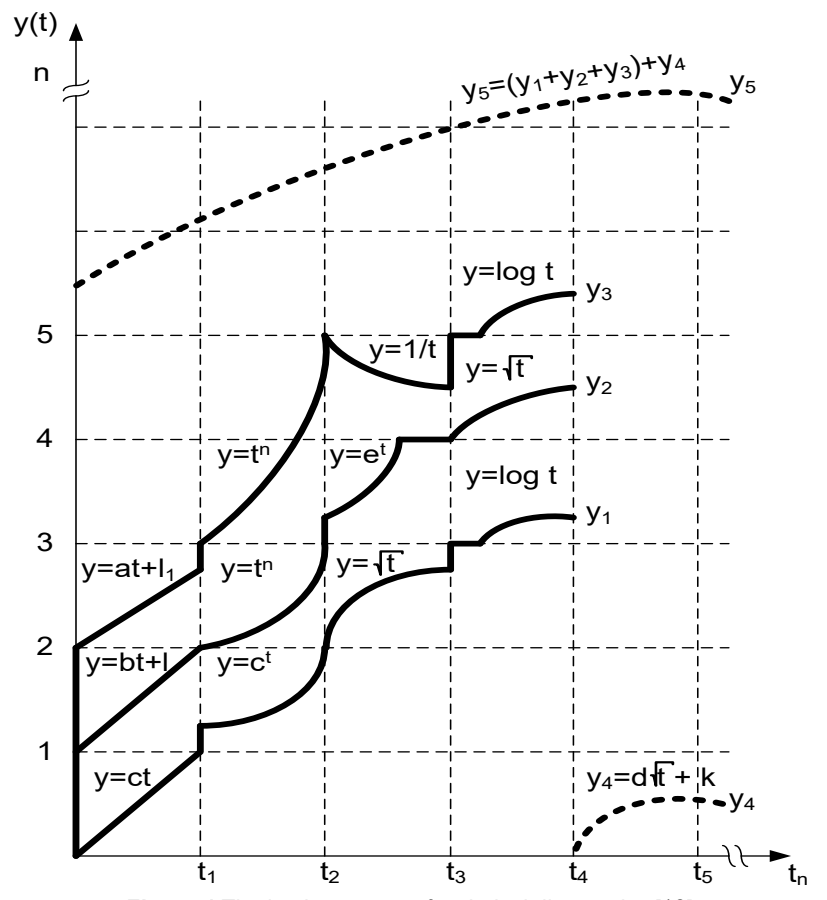

Figure 4 The basic process of technical diagnostics [12]

Fig. 4 shows one complex technical system with three production lines and four stages in each line. The technical system has lines and phases where the production function of that phase is shown at each stage. The production function shows the dependence of the movement of costs over time. Such an approach enables the mathematical simulation and monitoring of production, thereby setting the optimum combination of capacity utilization. In addition to the picture, the basic elements of collaboration, work execution standards, working methods, maintenance facilities and equipment, personnel and their experience and education must be elaborated. Fig. 4 also shows that the costs are summed up by the production stages and this must be all programmed in software. Furthermore, the complete business and maintenance process is monitored. The external partner has constant insight into the movement of the process, hence any deviation can be identified and the cause determined. For example, if unplanned costs occur at a certain stage, which can be caused by increased electricity consumption at that stage, this may be a problem in the rotational parts of a particular stage of production. Given the external partner's equipment, it is possible to provide immediate troubleshooting instructions. Moreover, costs are constantly monitored so that capacity can be adjusted to the optimal cost. When it comes to the technical diagnostics of the system, then there is a great deal of data to consider and prepare the system for more efficient and effective operation.

The complete process starts with the ordering of the business and ends with the result or benefits for the outsourcing service recipient. In order to maintain such a system, it is necessary to demonstrate the possession of adequate equipment as well as personnel who can perform complex tasks on the maintenance of technical systems. Furthermore, working methods to ensure productivity and 
quality are extremely important. Fig. 5 shows a management system that provides monitoring and operation with the support of appropriate hardware and software.

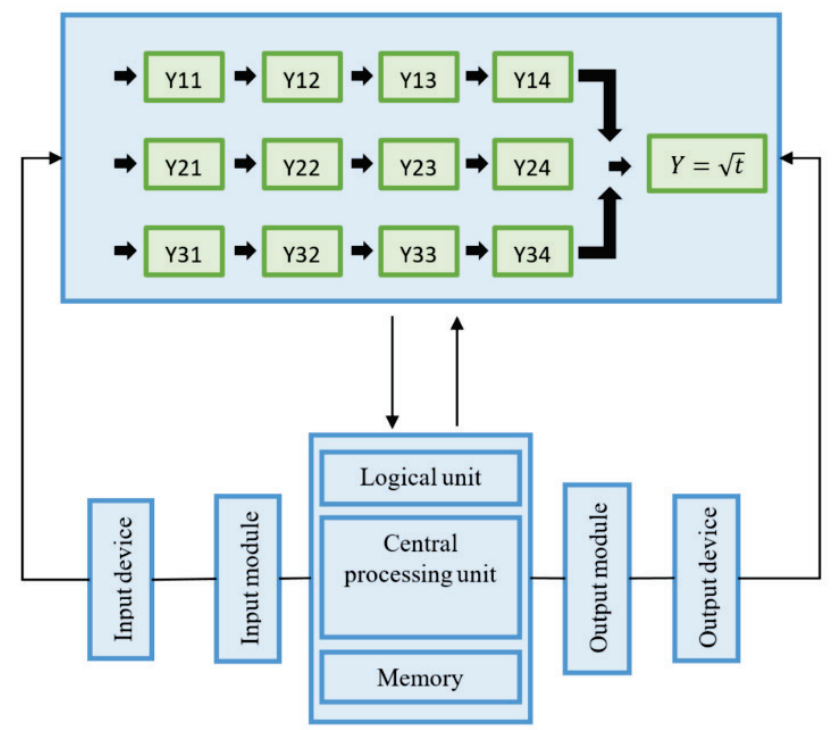

Figure 5 The basic process of technical diagnostics [13]

Appropriate hardware and software that will perform the monitoring function should be upgraded to this process, and the obtained data will be of great use for technical diagnostics. The development stage of information technology enables a wireless link between the maintenance provider and the technical system where partners have constant control over the functioning of the production and business process.

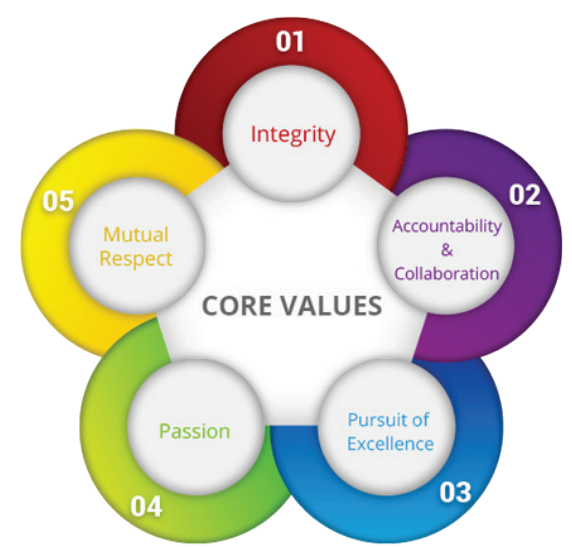

Figure 6 The basic process of technical diagnostics [14]

When the facility is a complex technical system, it is obvious that maintenance, especially technical diagnostics, should be performed by an external partner. That is why the external partner should be in constant contact, as any interruption of the system operation can cause high costs or losses. Moreover, an information and communication system is needed to support a permanent wireless link with the client. This creates a synergistic relationship in which the provider and the recipient of the service have several beneficial effects. Ideally, Fig. 6 shows a synergistic approach to the relationship between the client and the outsourcing service provider. The content of the picture shows that there is a synergy between the provider and the outsourcing service provider, which ensures the quality and efficiency of the service, as well as other benefits of common interest. This applies in particular to the development of the system and the tendency towards community, the pursuit of excellence, but a common interest also develops. As the picture suggests, more mutually beneficial values can be appreciated, which only confirms the possibility of long-term cooperation.

\section{OUTSOURCING THE INFORMATION AND COMMUNICATION PROCESS WHEN MAINTAINING A COMPLEX TECHICAL SYSTEM}

For convenience, Fig. 7 shows one integrated information and communication system where a maintenance system is connected to the management system. From it, you can see how an external partner is connected in the form of a contact centre where the flow of each operation in all lines of the production process is monitored. The very indication that the process is not proceeding according to the lawfulness of its production function warns that a problem is occurring and can be acted upon. In this regard, software may be set up so that, in accordance with the disturbance in the movement of the production function, it may suggest action to eliminate the problem. In particular, it should be noted that the service provider may be affiliated with research centres and expert teams. In this way, the external partner can effectively reach all the necessary information, but he may also have other necessary resources when needed.

A basic prerequisite for maintaining the state of a complex technical system is a secure connection and a particularly wireless (Internet) connection. Fig. 7 shows one possibility of a connection of an external partner with a complex technical system in which the connection between the system and the external partner is constantly made and the state or functioning of the technical system is monitored. It should be noted that the personnel at the service recipients have the opportunity to be informed about the functioning of the system, but are in constant connection with an external partner so that they can perform certain hardware and software interventions in case the condition control shows certain problems in the functioning.

The complete process will be successful if everything is well prepared with particularly appropriate hardware and software from the recipient, but fully coordinated with the service provider. Since in this example there is a virtual connection between the provider and the recipient of the service, the process must be able to permanently secure against any connectivity problem. Particular attention should be paid to the security of information activities regarding harmful external influences such as various types of viruses. An external partner can more easily provide the necessary programs with his experience and knowledge that eliminate attempts to introduce problems into the information and communication system.

The expert teams in Fig. 7 can also offer elements of business intelligence, which in this case is a way of 
delivering the right information in the right format to the right hands at the right time [15].

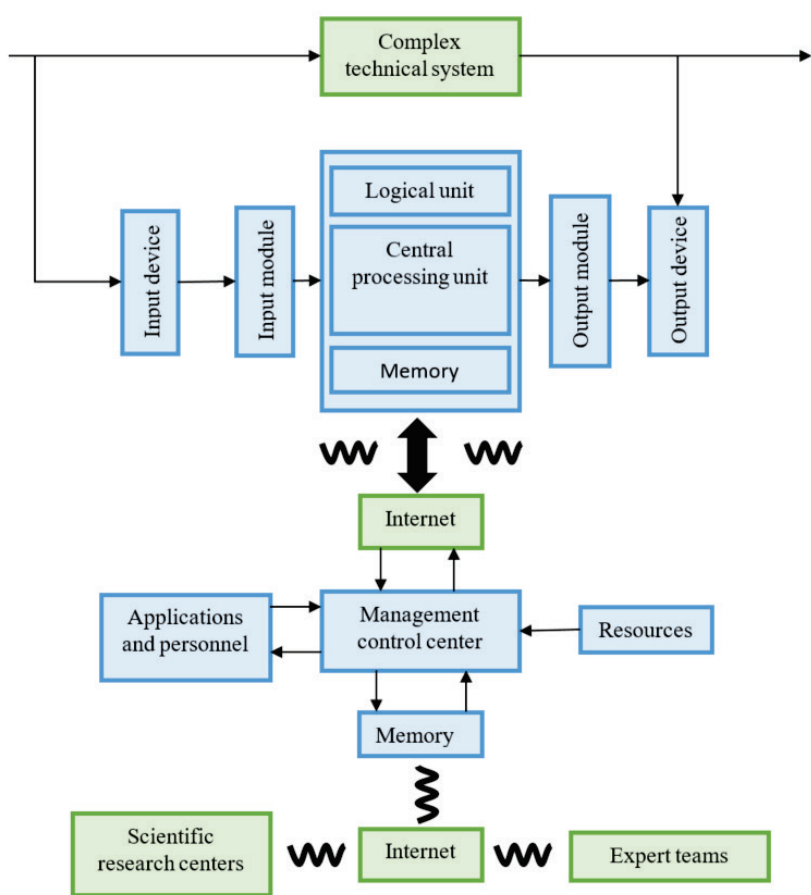

Figure 7 The basic process of technical diagnostics

Securing a virtual connection between the user and the provider can be addressed by the afore-mentioned CRM program. Moreover, with this or a similar software package, a permanent connection can be ensured between the service provider and some memory base, research or excellence centre.

According to the figure shown, the provider, unlike the recipient, usually has more educated staff, sophisticated equipment and a large memory base. Furthermore, the provider has a synergistic relationship with external memories, research centres and expert teams. This enables its high level of technology in terms of monitoring the state of production and functioning, and especially the maintenance of a complex technical system. The organization of the proposed approach ensures an extremely effective information and communication flow between the recipient and the provider.

Outsourcing can be continually refined in synergies between recipients and service providers and through the development of techniques and technology. In this respect, the outsourcing service provider, when maintaining complex technical systems, must consider the following factors [16]:

1. Customer satisfaction, which is the first and foremost factor

2. Measurability, which means that not only customer satisfaction is important, but also the ability to measure

3. Financial savings because for the client, this is the most important reason for outsourcing, in addition to quality

4. Sharing risks with a partner, which means that success and failure should be shared with the partner
5. The quality of the work done must be unquestionable and this is possible through continuous improvement of the provider in terms of new methods, resources and especially personnel

6. Consistency implies the continued availability of partner capacity according to the client's contractual requirements

7. Stability and diversity arising from the security of the contractual relationship, regardless of the changes caused by external influences

8. Predictability, which means that jobs, deadlines and other contractual clauses need to be precisely defined

9. The ability and expertise of the staff, which is possible through continuous training in a specific field of technical diagnostics

10. The speed and efficiency of responding to sudden needs as this avoids unnecessary costs and losses for clients.

Internet communication has other advantages such as the following [17]:

- 24-hour access to information

- Communication is interactive

- Clients are global; individual interaction is also possible

- It enhances dialogue while restricting communication.

The previous analysis of influential factors shows that in such complex processes, new methods and software should be explored. Moreover, achievements in the field of IT equipment should be monitored, as technological development can always offer even more modern solutions.

\section{CONCLUSION}

On the basis of analysing the previous text and illustrations, more conclusions can be drawn. First of all, the importance of state-of-the-art maintenance and technical diagnostics in complex technical systems is highlighted and documented. Maintaining such systems requires special staff and very complex equipment and operating methods and procedures. Moreover, and in particular for technical diagnostics, special time should be provided and staffing from regular production should be engaged, which creates additional costs with questionable labour productivity. Therefore, engaging an external partner is more effective, as this ensures quality and lower costs and greater system efficiency.

The paper presents examples of the information and communication connection when conducting business with external partners or outsourcing. In this regard, an information and communication process has been set up, and it should be monitored by appropriate hardware and software. In particular, it may be noted that an external partner can be associated with various external memory and research centres, which only increases its quality and reasons for engaging in the maintenance of a complex technical system. 


\section{REFERENCES}

[1] http://web.efzg.hr/pods/start.pod/10\%/20.OUTSOURCING\%/ 20.2007.pdf

[2] http://savjetnik.ba/kutak-za-klijente/17438-2/

[3] Lacković, Z. (2014). OUTSOURCING u održavanju, Građevinski fakultet, Osijek, 6.

[4] Lacković, Z. (2014). OUTSOURCING u održavanju, Građevinski fakultet, Osijek, 8.

[5] http://www.prekovremena.com.item/outsourcing

[6] Earl, M. J. (1996). The risk of outsourcing IT, Sloan Management Review, 37/3

[7] Lacković, Z. (2015). Sustav tehničke dijagnostike, Albert, Osijek, 37.

[8] Panian, Ž. (2003). Odnosi s klijentima u e-Poslovanju, Sinergija, Zagreb, 115.

[9] Panian, Ž. (2003). Odnosi s klijentima u e-Poslovanju, Sinergija, Zagreb, 131.

[10] Panian, Ž. (2003). Odnosi s klijentima u e-Poslovanju, Sinergija, Zagreb, 121.

[11] Mansfield, E. (1991). Microeconomics: Theory Applications, W.W. Norton \& Company Inc, New York-London, 172-173

[12] Lacković, Z. (2015). Upravljanje tehničkim procesima, Akademija tehničkih znanosti Hrvatske, Zagreb, 225.

[13] Lacković, Z. (2017). Lean građevinarstvo, Alberta, Osijek, 124

[14] https://wboutsourcing.com/wp-content/uploads/2017/01/ outsource-core-values-images.png

[15] Murfit, S. Using Business Intelligence, www.digitrends.net/scripts

[16] Brdarević, S. \& Omerhodžić, F. (2009). Outsourcing - The way to increase the efficiency, Universiti of Zenica, 6. Scientific conference "Kvalitet 2009", Neum, B\&H, 172

[17] Rowley, J. (2001). Remodeling Marketing Communications in an Internet Environment, Internet Research: Electronic Networking Applications and Policy, 11(3), 203-212 https://doi.org/10.1108/10662240110397017

\section{Authors' contacts:}

Drago Kraljević, PhD, Assistant Professor

Josip Juraj Strossmayer University of Osijek, Faculty of Agrobiotechnical Sciences Osijek, Vladimira Preloga 1, 31000 Osijek, Croatia

drago.kraljevic@fazos.hr

Krešimir Lacković, PhD, Assistant Professor

University North,

Trg dr. Žarka Dolinara 1, 48000 Koprivnica, Croatia

kresimir.lackovic@unin.hr

Robert Šojo, mag. ing. comp

(Corresponding author)

Josip Juraj Strossmayer University of Osijek, Faculty of Electrical Engineering,

Computer Science and Information Technology in Osijek

Cara Hadrijana 10b, 31000 Osijek, Croatia

robert.sojo@ferit.hr 